Review

\title{
An emerging class of air pollutants: Potential effects of microplastics to respiratory human health?
}

\author{
Luís Fernando Amato-Lourenço ${ }^{\mathrm{a}, \mathrm{b}, *}$, Luciana dos Santos Galvão ${ }^{\mathrm{c}}$, Letty A. de Weger ${ }^{\mathrm{d}}$, Pieter S. Hiemstra ${ }^{\mathrm{d}}$, \\ Martina G. Vijver ${ }^{\mathrm{e}}$, Thais Mauad ${ }^{\mathrm{a}, \mathrm{b}}$ \\ a Institute of Advanced Studies (IEA) Global Cities Program, University of Sao Paulo, Sao Paulo, Brazil \\ b Department of Pathology, Faculty of Medicine, University of São Paulo, São Paulo, Brazil \\ c Chemical Analyses Laboratory, Institute for Technological Research (IPT), São Paulo, Brazil \\ d Department of Pulmonology, Leiden University Medical Center, Leiden, the Netherlands \\ e Institute of Environmental Sciences, Leiden University, Leiden, the Netherlands
}

\section{H I G H L I G H T S}

- Plastic fragments are dispersed in air, and can be inhaled.

- There is limited information on the distribution of microplastics in air samples.

- They may cause adverse effects on the respiratory system and beyond.

- The exposure risk of inhaled MPs for human (respiratory) health is unresolved.
G R A P H I C A L A B S T R A C T

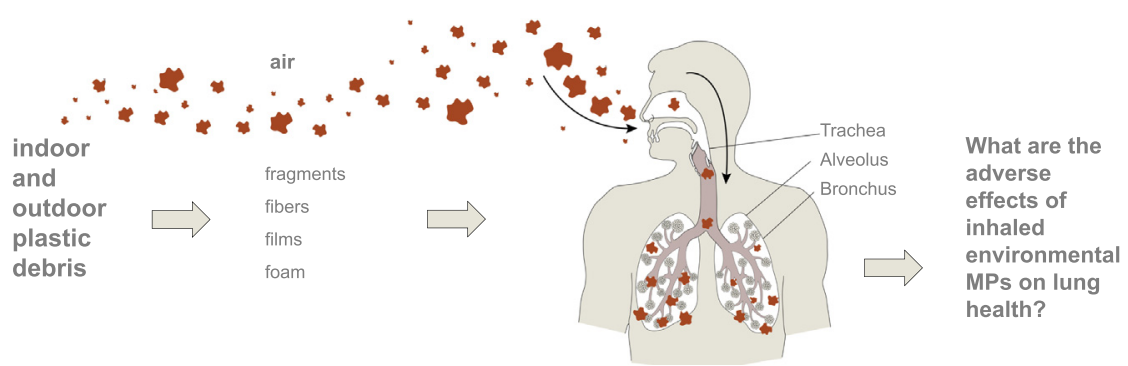

\begin{abstract}
A B S T R A C T
It is increasingly recognized that the ubiquity of convenient single-use plastic has resulted in a global plastic pollution challenge, with substantial environmental and health consequences. Physical, chemical, and biological processes result in plastic weathering, with eventual formation of debris in the micro to nano size range. There is an increasing awareness that plastic fragments are dispersed in the air and can be inhaled by humans, which may cause adverse effects on the respiratory system and on other systems. Urban environments are often characterized by high concentrations of fine airborne dust from various sources. To date, however, there is limited information on the distribution, shape, and size of microplastics in the air in urban and other environments. In this article, we review and discuss our current understanding of the exposure characteristics of airborne plastic debris in urbanized areas, focusing on concentration, size, morphology, presence of additives and distributions of different polymers. The natural and extend data are compiled and compared to laboratory-based analyses to further our understanding of the potential adverse effects of inhaled plastic particles on human health.
\end{abstract}

(c) 2020 Elsevier B.V. All rights reserved.

\footnotetext{
* Corresponding author at: Department of Pathology, Experimental Air Pollution Laboratory, LIM05 - School of Medicine, University of São Paulo - São Paulo, Av. Dr. Arnaldo 455, $1^{\circ}$ andar, sala 1155, Cerqueira César, São Paulo, SP CEP 01246-903, Brazil.

E-mail address: luisfamato@usp.br (L.F. Amato-Lourenço).
} 


\section{Contents}

1. Rationale......................................................2

2. Microplastics in the atmosphere: sources and fate . . . . . . . . . . . . . . . . . . . . . . . . . . . . . . . . . . 2

3. Potential effects on human health. . . . . . . . . . . . . . . . . . . . . . . . . . . . . . . . . . . . . . . . . . . . . 4

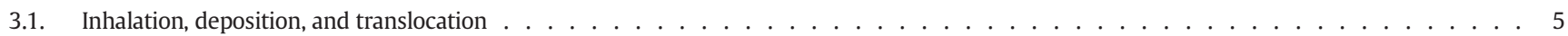

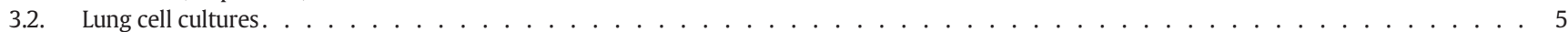

4. Emerging pollutants? . . . . . . . . . . . . . . . . . . . . . . . . . . . . . . . . . . . . . . . . . 5

Declaration of competing interest . . . . . . . . . . . . . . . . . . . . . . . . . . . . . . . . . . . . . . . . 6

Acknowledgements . . . . . . . . . . . . . . . . . . . . . . . . . . . . . . . . . . . . . . 6

References. . . . . . . . . . . . . . . . . . . . . . . . . . . . . . . . . . . . . . 6

\section{Rationale}

Humans use plastic because it is highly convenient (Hahladakis et al., 2018). Consequently, plastic debris is found throughout the world (Andrady, 2017; Eerkes-Medrano et al., 2015; Dris et al., 2016; Mahon et al., 2017; Bläsing and Amelung, 2018). Plastics are environmentally persistent. However, once released into the environment, they are exposed to continuous processes such as chemical weathering, photooxidation, biological decomposition and mechanical forces, which affect their structural integrity and result in fragmentation (Hidalgo-Ruz et al., 2012; Kubowicz and Booth, 2017). More than 4000 chemicals are currently used in plastic food packaging alone (Zimmermann et al., 2019). With more than 5000 different types of plastic on the market, the number of chemicals used to make plastics is likely larger (Zimmermann et al., 2019). Plastic debris (subsequently referred to as microplastics (MPs)) is therefore highly heterogeneous in terms of chemical composition, diameter, shape, specific density, and colour. These characteristics are key factors for their environmental distribution and bioavailability (Rocha-Santos and Duarte, 2015). Fragments, fibres and films are the most common shapes of plastic debris found in different environments worldwide (Wagner and Lambert, 2018). In addition to the presence of various additives, MPs also sorb hydrophobic organic contaminants (HOCs) (Wright and Kelly, 2017; Gasperi et al., 2018; Wardrop et al., 2016). Sorption of elements such as cadmium, zinc, nickel, and lead may also occur (Wright and Kelly, 2017; Rochman et al., 2014). MPs are considered priority pollutant vectors in the Stockholm and Basel Convention based on their potential adverse health effects (Gallo et al., 2018).

In addition to sorbing various toxicants, exposure of MPs to different environmental conditions may enable the formation of microbial biofilms on these MPs (Besseling et al., 2017; Foulon et al., 2016). Biofilm not only can significantly modify the physical properties of MPs, such as size and density (McCormick et al., 2014), but can also result in MPs serving as a vector for microbial pathogens (Foulon et al., 2016).

Due to their increasing presence in the environment and their ubiquitous distribution, MPs are among the most prominent environmental problems faced by government agencies around the world (Catarino et al., 2018; Nizzetto et al., 2016).

This review addresses the role of MPs as an emerging airborne pollutant with emphasis on the potential effects of inhaled MPs on human health. Although exposure to microplastics, for example, through ingestion of food can also have adverse health effects, this review is focused on microplastics as an inhaled toxicant and/or airborne vector for toxicants and pathogens. To this end, we first discuss the source and fate of microplastics in the air, based on studies with both indoor and outdoor sources. We then discuss their potential effects of inhalation on human health.

\section{Microplastics in the atmosphere: sources and fate}

Despite their importance, data on the distribution, shape and size of MPs in the atmosphere remains disjointed (Gasperi et al., 2018). Several sources can contribute to the release of MPs into the air, including the synthetic fabrics from clothing, tire erosion (especially from automobiles and trucks), household objects, waste incineration, building materials, sewage sludge, landfills, abrasive powders, 3D printing, and the resuspension of polymer fragments in urban dust (Catarino et al., 2018; UNEP, 2016). Fig. 1 shows the main sources of atmospheric MPs.

In the few reported studies that have characterized the morphology of MPs in the atmosphere, fibres (length $>5 \mu \mathrm{m}$, with $3 \mu \mathrm{m}$ length to diameter) have been the most commonly reported form (Dris et al., 2015; Dris et al., 2016; Cai et al., 2017). The increasing use of synthetic fibres with a diameter of $1-5 \mu \mathrm{m}$ by the textile industry has contributed directly and indirectly to textiles as a source of fibrous MPs (Gasperi et al., 2018). Nylon, polyester, polyolefin, and acrylic are typical manmade microfibres. Their release into the atmosphere is related to the use of textiles and the washing/drying process (Cesa et al., 2017). A single garment may release approximately 1900 fibres per wash (Browne et al., 2011). Industrially, cutting and grinding processes for polymeric materials can contribute to the formation and release of these particles in the air (Wright and Kelly, 2017).

MPs may also be released into the atmosphere as a result of winddriven transport from dried sludge by-products applied to agriculture soils (Kasirajan and Ngouajio, 2012). It is known that synthetic fibres, particles, and microbeads can be found in the sludge of wastewater treatment plants (WWTPs) (Li et al., 2018; Mahon et al., 2017) and may subsequently become airborne.

In cities, MPs accumulate in soil and road dust. Polymeric materials of low density may be easily suspended/resuspended in the atmosphere by wind and vehicular traffic flow (Abbasi et al., 2018). Automotive wear and tear from car tyres are recognized as a source of microplastics in the atmosphere through mechanical abrasion (Kole et al., 2017). Synthetic rubber consists of a hydrocarbon-based polymer (styrene-1.3butadene rubber (SBR)). Material generated by automotive tire abrasion is commonly reported as a particulate matter (PM) constituent in air pollution studies (Wright and Kelly, 2017). Tyre wear particles may represent between 0.8 and $8.5 \%$ of PM10 mass fraction and $1-10 \%$ of PM2.5 in the air (Panko et al., 2019). In the Netherlands, it is estimated that $17,000 \mathrm{t}$ of rubber tyre-wear are released into the environment every year (Verschoor, 2014). In Germany, emissions can reach up to 92,594 t per year (Kole et al., 2017). The estimated global average of per capita tyre wear emissions is $0.81 \mathrm{~kg}$ per year (Kole et al., 2017).

Modelling 3D printers are another potential source of MPs in the air. Fused deposition modelling (FDM) printers commonly use filament materials such as thermoplastics (acrylonitrile butadiene styrene (ABS), polylactic acid (PLA), polyamide (nylon) and polyethylene terephthalate (PET)). During the printing process the emission of nonengineered nano or ultrafine particles may occur. A study by Zhang et al. (2017) reported a particle concentration of up to 106 particles/ $\mathrm{cm}^{3}$ with mean particle sizes of 20 to $40 \mathrm{~nm}$ during an experiment where a 3D printer using acrylonitrile butadiene styrene (ABS) filaments was run inside a test chamber.

Although some studies report specific sources of MPs in the atmosphere, few investigations have quantified and characterized the presence of MPs in urban air (Prata, 2018). A study in the Greater Paris 


\section{Sources of indoor and outdoor plastic debris}

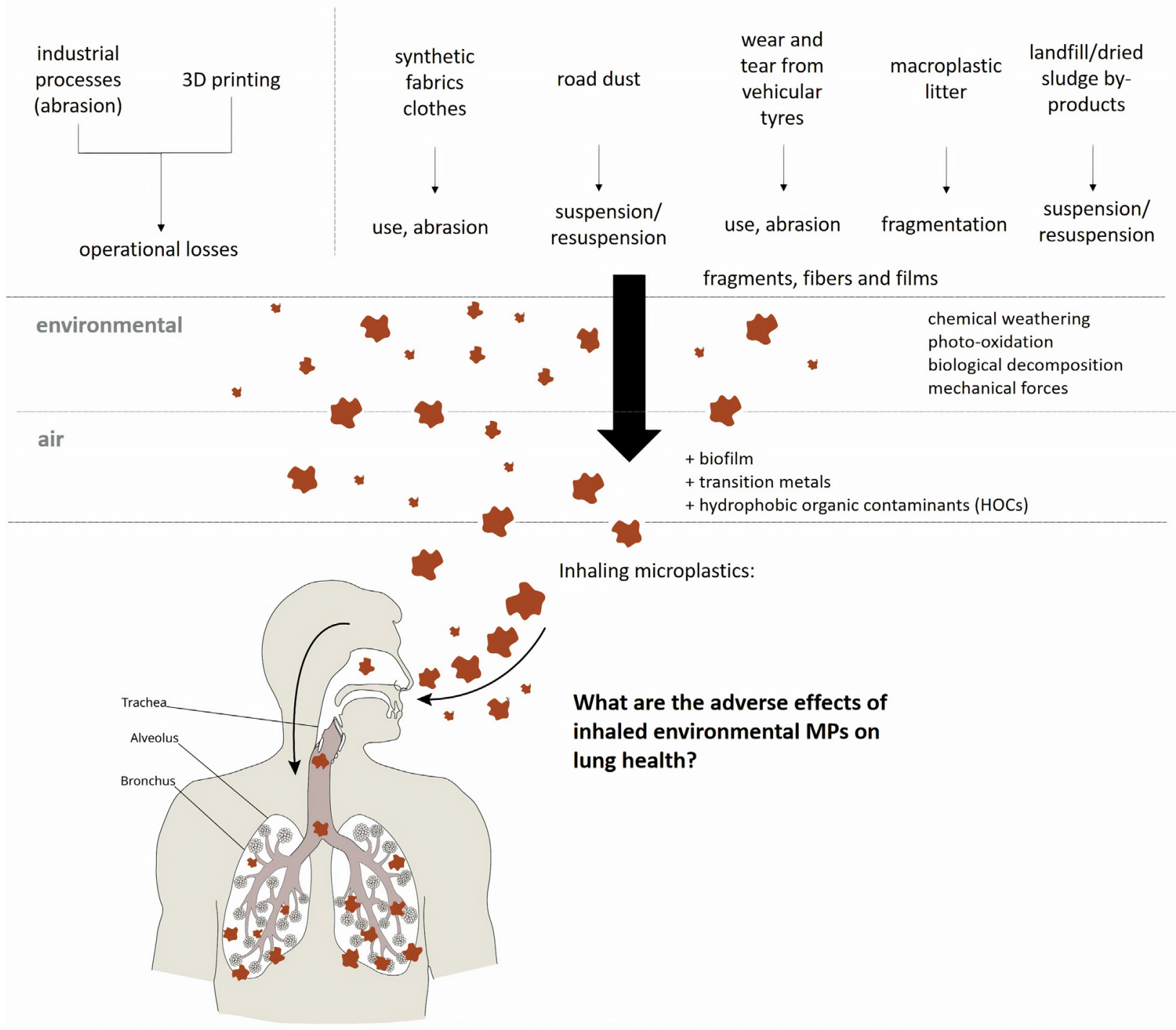

Fig. 1. Main sources of indoor and outdoor plastic debris released into the air and subject to human inhalation.

region analysed synthetic fibres present in the atmosphere using passive sampling. They reported the deposition of 29-280 particles $/ \mathrm{m}^{2} /$ day or 3.5-7.6 $\times 10^{10} \mathrm{MPs} / \mathrm{year}$ (Dris et al., 2015). Cai et al. (2017) reported that in the city of Dongguan (China), the concentration of fibrous and non-fibrous MPs from atmospheric deposition varied from 175 to 313 particles $/ \mathrm{m}^{2} /$ day. The length of most fibres ranged from 200 to $700 \mu \mathrm{m}$. A study conducted by Liu et al. (2019) in Shanghai investigated the potential source and spatial distribution of atmospheric MPs using an active suspended particulate sampler. Fibres comprised $67 \%$ of all MPs along with fragments (30\%) and granules (30\%). Synthetic compounds comprised $54 \%$ of the observed particles. In contrast, Stanton et al. (2019) reported that atmospheric depositions sampled from the roof of three campuses of the University of Nottingham (UK) had a high prevalence of natural textile fibres (97.7\%) compared to extruded textile fibres. In London, Wright et al. (2020) found 15 different polymers in the air with deposition rates ranging from 575 to 1008 particles $/ \mathrm{m}^{2} /$ day. The large majority of observed MPs in this study were fibres (92\%).

Abbasi et al. (2018) analysed dust deposits collected in Asaluyeh, Iran, and found an abundance of fibrous MPs (approximately 1 particle per $\mathrm{m}^{3}$ ) with sizes ranging from $2 \mu \mathrm{m}-100 \mu \mathrm{m}$. Dehghani et al. (2017) detected 88 to 605 polymeric fragments, ranging in size from 250 to
$500 \mu \mathrm{m}$, for every $30 \mathrm{~g}$ of road dust deposited on the streets of the central district of Tehran (Iran).

Outdoor airborne MPs levels are likely to be underestimated as they may simply be aggregated with other particles as a component fraction of atmospheric particulate matter (Prata, 2018). So far, no studies have reported the overall contribution of microplastics as a fraction of atmospheric PM. Particle size, density, meteorological factors and geographic factors, such as precipitation rates, wind speed and direction, temperature, and urban topography, may directly affect the behaviour, transport, and residence time of MPs in the atmosphere (Prata, 2018).

Furthermore, airborne microplastics are a potential source of microplastic pollution in marine environments. It is estimated that between 1.15 and 2.41 million tonnes of plastic waste enter the ocean every year from rivers (Lebreton et al., 2017). Airborne MPs may also enter waterways by deposition. Conversely, it is not known to what extent water-derived MPs can be a source of airborne MPs. Table 1 shows the current reported characteristics of observed microplastics in the air.

A preliminary study by our group (unpublished) of a high vehicular traffic street in São Paulo, Brazil, detected the presence of different polymer fibres in the air (Fig. 2).

Most human exposure to airborne MPs may occur indoors (Catarino et al., 2018). This has important consequences because Americans and 
Table 1

Characteristics of naturally weathered plastic particles observed in the air

\begin{tabular}{|c|c|c|c|c|c|c|}
\hline Study & Study site & Environment & Sampling approach & Polymer types $^{a}$ & Shape & Colours \\
\hline Dris et al. (2016) & Paris & Outdoor & Atmospheric deposition - Passive sampling & PET, PA & Fibre & $\mathrm{N} / \mathrm{A}$ \\
\hline Cai et al. (2017) & Dongguan & Outdoor & Atmospheric deposition - Passive sampling & PE, PP, PS & $\begin{array}{l}\text { Fibre, foam, } \\
\text { fragment, film }\end{array}$ & $\mathrm{N} / \mathrm{A}$ \\
\hline Dris et al. (2017) & Paris & Indoor/outdoor & Atmospheric deposition - Passive sampling & PP, PA, PE & Fibre & $\mathrm{N} / \mathrm{A}$ \\
\hline Zhou et al. (2017) & Yantai & Outdoor & Atmospheric deposition - Passive sampling & PET, PE, PVC, PS & $\begin{array}{l}\text { Fibre, foam, } \\
\text { fragment, film }\end{array}$ & White, black, red, transparent \\
\hline Dehghani et al. (2017) & Tehran & Outdoor & Street dust & - & $\begin{array}{l}\text { Fibre, spherules, } \\
\text { fragment }\end{array}$ & $\begin{array}{l}\text { Transparent, red, blue, green, } \\
\text { white, yellow, orange, pink, grey }\end{array}$ \\
\hline Catarino et al. (2018) & Edinburgh & Indoor & Atmospheric deposition - Passive sampling & - & Fibre & - \\
\hline Liu et al. (2019) & Shanghai & Outdoor & Total suspended particulate sampler & $\begin{array}{l}\text { PET, PE, PES, PAN, } \\
\text { PAA, RY, EVA, EP, } \\
\text { ALK }\end{array}$ & $\begin{array}{l}\text { Fibre, fragment, } \\
\text { granule }\end{array}$ & $\begin{array}{l}\text { Yellow, grey, blue, black, red, } \\
\text { transparent, brown, green, }\end{array}$ \\
\hline Stanton et al. (2019) & $\begin{array}{l}\text { Nottingham } \\
\text { region }\end{array}$ & Outdoor & Atmospheric deposition - Passive sampling & $\mathrm{N} / \mathrm{A}$ & Fibre & Black/grey, blue \\
\hline Abbasi et al. (2018) & Asaluyeh & Outdoor & $\begin{array}{l}\text { Street dust/suspended dust - PM ambient } \\
\text { filter sampler }\end{array}$ & - & $\begin{array}{l}\text { Fibre, spherules, } \\
\text { fragment, film }\end{array}$ & $\begin{array}{l}\text { White-transparent, red-pink, } \\
\text { blue-green, black-grey, } \\
\text { yellow-orange }\end{array}$ \\
\hline Wright et al. (2020) & $\begin{array}{l}\text { Central } \\
\text { London }\end{array}$ & Outdoor & Atmospheric deposition - Passive sampling & $\begin{array}{l}\text { PAN, PES, PA, PP, } \\
\text { PVC, PE, PET, PS, } \\
\text { PUR, PPR }\end{array}$ & $\begin{array}{l}\text { Fibre, fragment, } \\
\text { film, granules, } \\
\text { foams }\end{array}$ & $\mathrm{N} / \mathrm{A}$ \\
\hline
\end{tabular}

a PET: polyethylene terephthalate, PE: polyethylene, PES: polyester, PAN: polyacrylonitrile, PAA: poly(N-methyl acrylamide), RY: rayon, EVA: ethylene vinyl acetate, EP: epoxy, ALK: alkyd resin, PP: polypropylene, PA: Polyamide, PS: polystyrene, PVC: polyvinyl chloride, PUR: polyurethane, PPR: polymerized petroleum resin.

Europeans spend on average $90 \%$ of their time indoors, whether at home or at work (ASHRAE, 2010; E.C., 2003). A study conducted by Vianello et al. (2019) assessed the exposure of humans to indoor airborne microplastics using a breathing thermal manikin (simulating human respiration). All samples contained microplastics, primarily polyester (59-92\%), with concentrations between 1.7 and 16.2 particles $/ \mathrm{m}^{3}$. Similarly, Gasperi et al. (2015) found indoor MP concentrations ranging from 3 to 15 particles $/ \mathrm{m}^{3}$ in several private apartments and one office. The authors observed a gradient of indoor concentrations according to the sampling height, suggesting that MPs are resuspended from the floor due to human activity. Dris et al. (2017) found a concentration of fibres ranging from 190 to 670 fibres/mg in household dust collected using a conventional vacuum cleaner. Catarino et al. (2018) estimated fibre exposure during a meal (via dust fallout) of 13,731-68,415 airborne particles/year/capita in a household. High indoor concentrations may be explained by the presence of multiple MP sources (household objects and synthetic fabrics clothing) and the various mechanisms involved in their dispersion such as ventilation rate, airflow, room partition and climatic conditions (Dris et al., 2016; Catarino et al., 2018).

\section{Potential effects on human health}

Several studies have been published in recent years showing that MPs can have a deleterious toxicological effect on marine organisms through, for example, accumulation, obstruction, and inflammation in organs after translocation (Lei et al., 2018; Andrady, 2017; Syberg et al., 2017; Jeong et al., 2017; Sussarellu et al., 2016). However, many of the published toxicological studies use primary MPs; this method does not accurately represent the potential for damage from particles exposed to various environmental conditions (Wright and Kelly, 2017; Thompson et al., 2009). As discussed earlier in this review, plastic debris (secondary particles) is weathered through environmental exposure, which results in the formation of irregular shapes, a wide size distribution, and a variety of surface properties, and depends on their life cycle (comprising mechanical (erosion, abrasion), chemical (photooxidation, hydrolysis), and biological (degradation by microbes) processes).

Thus, the physical and chemical properties of secondary MPs differ from the primary microspheres often used for laboratory ecotoxicity testing. Studies testing the toxicology of secondary MPs are still lacking

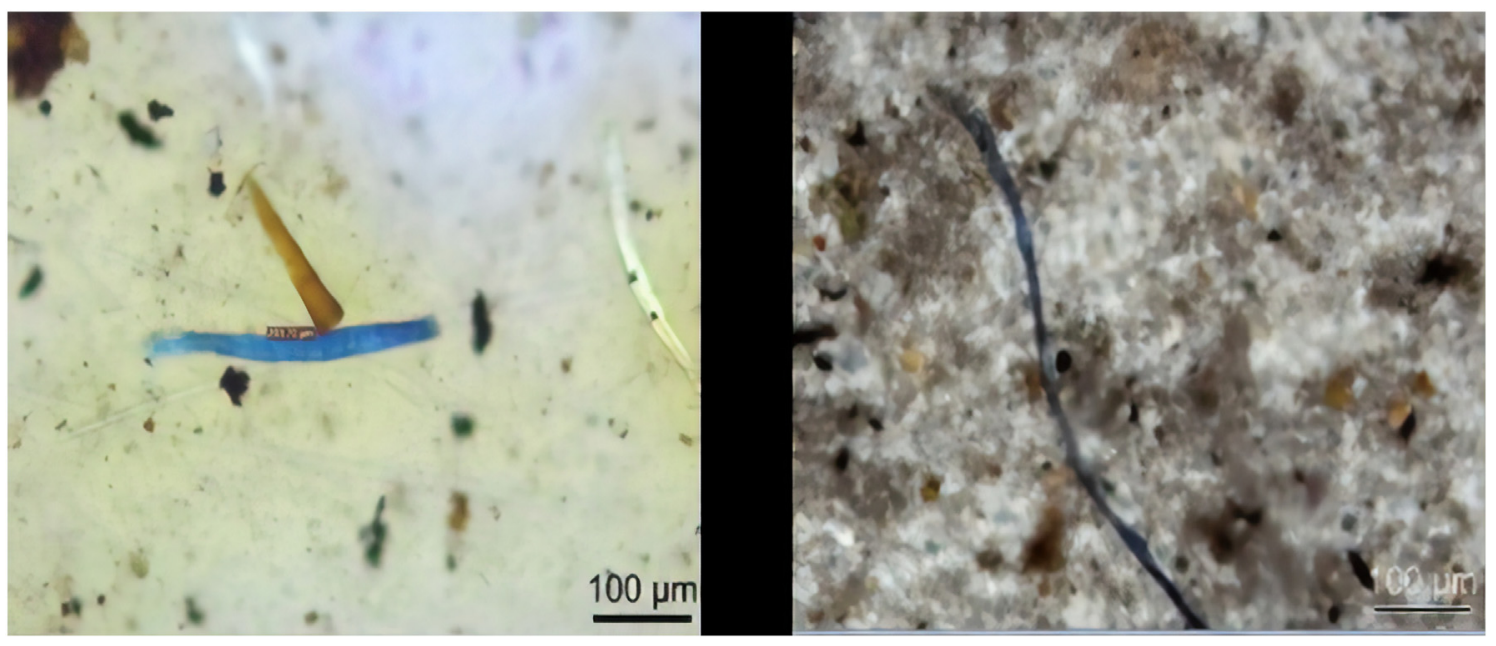

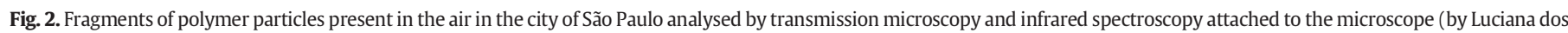
Santos Galvão, Chemical Analyses Laboratory, Institute for Technological Research (IPT), São Paulo, Brazil). 
due to technical limitations in isolating or mimicking their environmental characteristics in the laboratory. The complexity of chemical cocktails attached to plastic debris makes safety assessment a challenge. Most current studies focus on plasticizers such as bisphenol A (BPA) that are used as additives in polycarbonate plastic production and have been shown to leach and cause adverse health effects in humans through estrogenic activity (Vandenberg et al., 2007). Zimmermann et al. (2019) studied the toxicity of 8 commonly used plastics. The researchers used cell cultures to investigate the effects of the mix of chemicals in each product. They found that many plastics contain chemicals that induced general toxicity (six out of ten products), oxidative stress (four out of ten products) and endocrine-disrupting effects (three out of ten products).

\subsection{Inhalation, deposition, and translocation}

It is unclear to what extent exposure to airborne MPs is a threat to public health. Discussion of the potential adverse effects of airborne MPs on human health has only recently emerged (Wright and Kelly, 2017; Gasperi et al., 2018; Prata, 2018). The fate of inhaled MPs and their uptake in lung tissue is one of many unknowns. For example, there is only one report of polymeric fibres in human lung tissue, which was published more than 20 years ago (Pauly et al., 1998). In that study, polymeric and cellulosic fibres were found in $97 \%$ of malignant lungs ( $n=32 / 33)$ and in $83 \%$ of non-neoplastic lungs $(n=67$ / 81). The analysed fibres had lengths up to $135 \mu \mathrm{m}$ and showed little indication of deterioration, which may indicate their bioresistance and biopersistence in lungs. This single study shows that polymeric fibres have the potential to penetrate into deeper parts of the lungs and highlights the need for confirmation of these findings and more in-depth analyses. Importantly, studies on, for example, asbestos fibres have shown that despite their length, such fibres can be deposited in the alveolar region of the lung. This result is based on the finding that asbestos fibres with lengths ranging from 50 to $200 \mu \mathrm{m}$ were found in the alveolar cavity despite their long size (Barlow et al., 2017; Timbrell, 1965). Although physical characteristics of polymeric and asbestos fibres differ, both are known to resist biodegradation (Pauly et al., 1998).

Particle deposition in the lung is a function of its "aerodynamic diameter" (particle size expressed in terms of settling speed) (Donaldson et al., 1993). Fibre diameter plays a major role in its breathability, while length is a key determinant of its persistence and toxicity. Pleural mesotheliomas are usually associated with fibres over $8 \mu \mathrm{m}$ in length and less than $0.25 \mu \mathrm{m}$ in diameter (Donaldson et al., 1993). Furthermore, it is known that the efficiency of fibre deposition increases with a decrease in diameter (Donaldson et al., 1993).

Fibres can be deposited in terminal bronchioles, alveolar ducts, and alveoli, resulting in chronic inflammation, granulomas or fibrosis (Greim et al., 2001; Beckett, 2000). The severity of tissue damage is usually a function of an inhaled dose over time (Warheit et al., 2001). Greim et al. (2001) suggested that the interaction between cells and particles/ fibres can cause inflammation, which in turn induces cell proliferation and secondary genotoxicity due to the continuous formation of reactive oxygen species (ROS). Overproduction of ROS results in oxidative stress, causing chronic inflammation and contributing to the pathogenesis of lung diseases.

Fibre persistence in the lung is related to its aerodynamic properties (Tian and Ahmadi, 2013). The fibre length to diameter ratio determines their uptake by alveolar macrophages and affects mucociliary clearance rates. Usually, long, thin fibres are incompletely phagocytosed and are more biologically active than short fibres (Donaldson et al., 1993). These persistent particles can translocate into the epithelial layers (Donaldson et al., 2011) and induce acute or chronic inflammatory processes.

Occupational exposure studies associate inhalation of pristine MPs with an increased incidence of interstitial lung disease (Abbasi et al., 2018; Boag et al., 1999; Eschenbacher et al., 1999). Occupational exposure to polyvinyl chloride (PVC) dust was associated with exertional dyspnoea and decreased pulmonary function in factory workers (Soutar et al., 1980). A study conducted by Atis et al. (2005) evaluated the respiratory effects of occupational polypropylene flock exposure. The risk of respiratory symptoms increased 3.6-fold in polypropylene flocking workers when compared to controls. Lung biopsies from workers exposed to different airborne synthetic fibres (acrylic, polyester (terylene) nylon) revealed different degrees of inflammation, granulomas and interstitial fibrosis (Pimentel et al., 1975).

These observations from occupational medicine, combined with the recent detection of MPs in airborne samples, point to a possible risk for human exposure via inhalation. Collectively, these studies suggest that there may be a link between MP exposure and development of interstitial lung diseases. The initial triggers for development of interstitial lung diseases are largely unknown. Further research in this area may reveal whether naturally weathered MPs could serve as a trigger.

\subsection{Lung cell cultures}

Few studies have investigated the potential toxic effects of microand nanoplastic particles on cultured human epithelial lung cells as a model for pulmonary toxicology. Xu et al. (2019) evaluated the effects of polystyrene nanoparticles ( $25 \mathrm{~nm}$ and $70 \mathrm{~nm}$ diameter) on the human alveolar epithelial A549 tumour cell line. The results show that these nanoparticles can significantly affect cell viability, can activate inflammatory gene transcription, and can change the expression of proteins associated with cell cycle and pro-apoptosis. Dong et al. (2020) revealed that polystyrene MPs can cause inflammatory and cytotoxic effects in human lung epithelial BEAS-2B cells by inducing the formation of reactive oxygen species (ROS).

However, to date, there are no published in vitro studies of pulmonary toxicity based on environmentally relevant conditions or on primary lung cell cultures. The cited studies used pristine microplastic spheres.

\section{Emerging pollutants?}

Plastic waste is one of the greatest contemporary environmental challenges. Airborne MPs (fragments, fibres and membranes) have been reported in remote, desolated and uninhabited regions, such as the French Pyrenees (Allen et al., 2019), Rocky Mountain National Park, USA (Wetherbee et al., 2019), and regions of the Artic (Bergmann et al., 2019).

In light of the COVID-19 pandemic, concerns about plastic waste pollution in the healthcare system have increased due to an unprecedented demand for single-use products such as vinyl gloves, face masks, plastic ventilator components, visors, gowns, and bags; all of these products are produced from polymeric materials (Fadare and Okoffo, 2020). The global medical plastics market is projected to grow from USD 25.1 billion in 2020 to USD 29.4 billion by 2021 (Research and Markets, 2020). In China, as of Feb 2020, 14.8 million masks were being produced daily (Xinhuanet, 2020). Inadequate disposal of these materials is becoming a threat to waterways, soils and possibly also the air.

The usual methods of observation, detection and characterization of polymeric particles are limited by a size minimum of $50 \mu \mathrm{m}$, leaving important questions to be answered regarding the physical/chemical properties and toxicological potential of smaller particles. To date, few studies have quantified and characterized airborne MPs. The available data indicate that MPs are biopersistent, ubiquitous and numerous.

The exposure risk of inhaled MPs for human (respiratory) health is also unresolved. One of the main questions to be answered is whether and how naturally weathered inhaled MPs may cause or contribute to the pathogenesis of different pulmonary diseases. Data on exposure characteristics such as concentration, size, morphology, and distribution of different airborne polymers are prerequisites for understanding the potential effects of MPs on human health. 
Although occupational studies show pulmonary effects associated with MP inhalation, the doses tested in these studies are probably higher than those of actual environmental concentrations. However, an important difference is that sorption of co-pollutants such as transition metals, organic compounds, and pathogenic microorganisms is likely lower on the surface of occupational particles than on environmental particles. Many of the deleterious health outcomes associated with MPs may be related to the desorption of these contaminants in the respiratory system following inhalation. Another question to be addressed is whether inhaled MPs can translocate to the blood and/or be carried to mediastinal lymph nodes.

Given the heterogeneous characteristics, sources, and fates of MPs, it is necessary to reconceptualize microplastics as a new class of contaminant, rather than as a single pollutant - as suggested by Rochman et al. (2019). Combined with the realization that inhaled MPs constitute a significant threat to human health, as discussed in this review and an increasing number of reports, new avenues of research are needed to address the plastic pollution challenge.

\section{Declaration of competing interest}

The authors declare that they have no known competing financial interests or personal relationships that could have appeared to influence the work reported in this paper.

\section{Acknowledgements}

This study was supported by the São Paulo Research Foundation (FAPESP): projects 2019/03397-5 and 2019/02898-0.

\section{References}

Abbasi, S., Keshavarzi, B., Moore, F., Turner, A., Kelly, F.J., Dominguez, A.O., et al., 2018. Distribution and potential health impacts of microplastics and microrubbers in air and street dusts from Asaluyeh County, Iran. Environ. Pollut. 244, 153-164 (Oct 10).

Allen, S., Allen, D., Phoenix, V.R., Roux, G.L., Jiménez, P.D., Simonneau, A., Binet, S., Galop, D., 2019. Atmospheric transport and deposition of microplastics in a remote mountain catchment. Nat. Geosci. 12, 339-344.

Andrady, A.L., 2017. The plastic in microplastics: a review. Mar. Pollut. Bull. 119 (1), 12-22 (Jun 15).

ASHRAE, 2010. Guideline 10P, Interactions Affecting the Achievement of Acceptable Indoor Environments, Second Public Review. ASHRAE, Atlanta, USA.

Atis, S., Tutluoglu, B., Levent, E., Ozturk, C., Tunaci, A., Sahin, K., Saral, A., Oktay, I., Kanik, A., Nemery, B., 2005. The respiratory effects of occupational polypropylene flock exposure. Eur. Respir. J. 25, 110-117. https://doi.org/10.1183/09031936.04.00138403.

Barlow, C.A., Grespin, M., Best, E.A., 2017. Asbestos fiber length and its relation to disease risk. Inhal. Toxicol. 29 (12-14), 541-554. https://doi.org/10.1080/08958378. 2018.1435756

Beckett, W.S., 2000. Occupational respiratory diseases. N. Engl. J. Med. 342 (6), 406-413. https://doi.org/10.1056/nejm200002103420607.

Bergmann, M., Mützel, S., Primpke, S., Tekman, M.B., Trachsel, J., Gerdts, G., 2019. White and wonderful? Microplastics prevail in snow from the Alps to the Arctic. Sci. Adv. 5, eaax1157. https://doi.org/10.1126/sciadv.aax1157.

Besseling, E., Quik, J.T.K., Sun, M., Koelmans, A.A., 2017. Fate of nano- and microplastic in freshwater systems: a modeling study. Environ. Pollut. 220 (Pt A), 540-548 (Jan).

Bläsing, M., Amelung, W., 2018. Plastics in soil: analytical methods and possible sources. Sci. Total Environ. 612, 422-435 (Jan 15).

Boag, A.H., Colby, T.V., Fraire, A.E., Kuhn, C., Roggli, V.L., Travis, W.D., et al., 1999. The pathology of interstitial lung disease in nylon flock workers. Am. J. Surg. Pathol. 23 (12), 1539-1545 (Dec).

Browne, M.A., Crump, P., Niven, S.J., Teuten, E., Tonkin, A., Galloway, T., Thompson, R., 2011. Accumulation of microplastic on shorelines worldwide: sources and sinks. Environ. Sci. Technol. 45, 9175e9179. https://doi.org/10.1021/es201811s.

Cai, L., et al., 2017. Characteristic of microplastics in the atmospheric fallout from Dongguan city, China: preliminary research and first evidence. Environ. Sci. Pollut. Res. 24, 24928-24935.

Catarino, A.I., Macchia, V., Sanderson, W.G., Thompson, R.C., Henry, T.B., 2018. Low levels of microplastics (MP) in wild mussels indicate that MP ingestion by humans is minimal compared to exposure via household fibres fallout during a meal. Environ. Pollut. 237, 675-684 (Jun).

Cesa, F.S., Turra, A., Baruque-Ramos, J., 2017. Synthetic fibers as microplastics in the marine environment: a review from textile perspective with a focus on domestic washings. Sci. Total Environ. 598, 1116-1129.

Dehghani, S., Moore, F., Akhbarizadeh, R., 2017. Microplastic pollution in deposited urban dust, Tehran metropolis, Iran. Environ. Sci. Pollut. Res. Int. 24 (25), 20360-20371.

Donaldson, K., Brown, R.C., Brown, G.M., 1993. Respirable industrial fibres: mechanisms of pathogenicity. Thorax 48, 390-395.
Donaldson, K., Murphy, F., Schinwald, A., Duffin, R., Poland, C.A., 2011. Identifying the pulmonary hazard of high aspect ratio nanoparticles to enable their safety-by-design. Nanomedicine 6 (1), 143-156. https://doi.org/10.2217/nnm.10.139.

Dong, C.D., Chen, C.W., Chen, Y.C., Chen, H.H., Lee, J.S., Lin, C.H., 2020. Polystyrene microplastic particles: in vitro pulmonary toxicity assessment. J. Hazard. Mater 385, 121575. https://doi.org/10.1016/j.jhazmat.2019.121575 (Mar 5).

Dris, R., Gasperi, J., Rocher, V., Saad, M., Renault, N., Tassin, B., 2015. Microplastic contamination in an urban area: a case study in Greater Paris. Environ. Chem. 12 (5), 592.

Dris, R., Gasperi, J., Saad, M., Mirande, C., Tassin, B., 2016. Synthetic fibers in atmospheric fallout: a source of microplastics in the environment? Mar. Pollut. Bull. 104 (1-2) 290-293 (Mar 15).

Dris, R., Gasperi, J., Mirande, C., Mandin, C., Guerrouache, M., Langlois, V., Tassin, B., 2017 A first overview of textile fibers, including microplastics, in indoor and outdoor environments. Environ. Pollut. 221, 453-458.

E.C., European Commission, 2003. Indoor air pollution: new EU research reveals higher risks than previously thought. https://europa.eu/rapid/press-release_IP-03-1278_en. htm (Brussels, 5p).

Eerkes-Medrano, D., Thompson, R.C., Aldridge, D.C., 2015. Microplastics in freshwater systems: a review of the emerging threats, identification of knowledge gaps and prioritisation of research needs. Water Res. 75, 63-82 (May 15).

Eschenbacher, W.L., Kreiss, K., Lougheed, M.D., Pransky, G.S., Day, B., Castellan, R.M., 1999 Nylon flock-associated interstitial lung disease. Am. J. Respir. Crit. Care Med. 159 (6), 2003-2008 (Jun).

Fadare, O.O., Okoffo, E.D., 2020. Covid-19 face masks: a potential source of microplastic fibers in the environment. Sci. Total Environ. 737, 140279. https://doi.org/10.1016/j. scitotenv.2020.140279.

Foulon, V., Le Roux, F., Lambert, C., Huvet, A., Soudant, P., Paul-Pont, I., 2016. Colonization of polystyrene microparticles by Vibrio crassostreae: light and electron microscopic investigation. Environ. Sci. Technol. 50 (20), 10988-10996.

Gallo, F., Rossi, C., Weber, R., Santillo, D., Sousa, J., Ingram, I., Nadal, A., Romano, D., 2018. Marine litter plastics and microplastics and their toxic chemicals components: the need for urgent preventive measures. Environ. Sci. Eur. 30, 13. https://doi.org/ 10.1186/s12302-018-0139-z.

Gasperi, J., Dris, R., Mirande-Bret, C., Mandin, C., Langlois, V., Tassin, B., 2015. First overview of microplastics in indoor and outdoor air. Paper Presented at 15th EuCheMS International Conference on Chemistry and the Environment, Leipzig, Germany https://hal-enpc.archives-ouvertes.fr/hal01195546 (September).

Gasperi, J., Wright, S.L., Dris, R., Collard, F., Mandin, C., Guerrouache, M., et al., 2018. Microplastics in air: are we breathing it in? Curr. Opin. Environ. Sci. Health 1,1-5 (Feb).

Greim, H., Borm, P., Schins, R., Donaldson, K., Driscoll, K., Hartwig, A., Kuempel, E., Oberdorster, G., Speit, G., 2001. Toxicity of fibers and particles report of the workshop held in Munich, Germany, October 26-27, 2000. Inhal. Toxicol. 13, 737-754.

Hahladakis, J.N., Velis, C.A., Weber, R., Iacovidou, E., Purnell, P., 2018. An overview of chemical additives present in plastics: migration, release, fate and environmental impact during their use, disposal and recycling. J. Hazard. Mater. 344, 179-199 (Feb 15).

Hidalgo-Ruz, V., Gutow, L., Thompson, R.C., Thiel, M., 2012. Microplastics in the marine environment: a review of the methods used for identification and quantification. Environ. Sci. Technol. 46 (6), 3060-3075 (Mar 20).

Jeong, C.B., Kang, H.M., Lee, M.C., Kim, D.G., Han, J., Hwang, D.S., Souissi, S., Lee, S., Shin, K.H., Park, H.G., Leeb, J.S., 2017. Adverse effects of microplastics and oxidative stress-induced MAPK/Nrf2 pathway-mediated defense mechanisms in the marine copepod Paracyclopina nana. Sci. Rep. 7, 41323.

Kasirajan, S., Ngouajio, M., 2012. Polyethylene and biodegradable mulches for agricultura applications: a review. Agron. Sustain. Dev. 32 (2), 501-529.

Kole, P.J., Löhr, A.J., Van Belleghem, F.G.A.J., Ragas, A.M.J., 2017. Wear and tear of Tyres: a stealthy source of microplastics in the environment. Int. J. Environ. Res. Public Health 14, 1265. https://doi.org/10.3390/ijerph14101265.

Kubowicz, S., Booth, A.M., 2017. Biodegradability of plastics: challenges and misconceptions. Environ. Sci. Technol. 51 (21), 12058-12060 (Nov 7).

Lebreton, L.C.M., Van der Zwet, J., Damsteeg, J.-W., Slat, B., Andrady, A., Reisser, J., 2017. River plastic emissions to the world's oceans. Nat. Commun. 8, 15611.

Lei, L., Wu, S., Lu, S., Liu, M., Song, Y., Fu, Z., et al., 2018. Microplastic particles cause intestinal damage and other adverse effects in zebrafish Danio rerio and nematode Caenorhabditis elegans. Sci. Total Environ. 619-620, 1-8 (Apr 1).

Li, X., Chen, L., DongB, Mei Q., Dai, X., Ding, G., Zeng, E.Y., 2018. Microplastics in sewage sludge from the wastewater treatment plants in China. Water Res. 142, 75-85.

Liu, K., Wang, X., Fang, T., Xu, P., Zhu, L., Li, D., 2019. Source and potential risk assessment of suspended atmospheric microplastics in Shanghai. Sci. Total Environ. 675 462-471. https://doi.org/10.1016/j.scitotenv.2019.04.110 (Jul 20, Epub 2019 Apr 9).

Mahon, A.M., O'Connell, B., Healy, M.G., O'Connor, I., Officer, R., Nash, R., et al., 2017 Microplastics in sewage sludge: effects of treatment. Environ. Sci. Technol. 51 (2), 810-818 (Jan 17).

McCormick, A., Hoellein, T.J., Mason, S.A., Schluep, J., Kelly, J.J., 2014. Microplastic is an abundant and distinct microbial habitat in an urban river. Environ. Sci. Technol. 48 (20), 11863-11871 (Oct 21).

Nizzetto, L., Futter, M., Langaas, S., 2016. Are agricultural soils dumps for microplastics of urban origin? Environ. Sci. Technol. 50 (20), 10777-10779 (Oct 18).

Panko, J.M., Hitchcock, K.M., Fuller, G.W., Green, D., 2019. Evaluation of tire wear contribution to PM2.5 in urban environments. Atmos 10 (99). https://doi.org/10.3390/ atmos10020099.

Pauly, J.L., Stegmeier, S.J., Allaart, H.A., Cheney, R.T., Zhang, P.J., Mayer, A.G., et al., 1998. Inhaled cellulosic and plastic fibers found in human lung tissue. Cancer Epidemiol. Biomark. Prev. 7 (5), 419-428 (May).

Pimentel, J.C., Avila, R., Lourenço, A.G., 1975. Respiratory disease caused by synthetic fibres: a new occupational disease. Thorax 30 (2), 204-219. 
Prata, J., 2018. Airborne microplastics: consequences to human health? Environ. Pollut. 234, 115-126.

Research and Markets, 2020. Covid-19 Impact on the Medical Plastics Market by Type (Engineering Plastics and Standard Plastics), Application (Medical Disposables, Prosthetics, Medical Instruments \& Tools and Drug Delivery) and Region - Global Forecast to 2021. Report (58 p).

Rocha-Santos, T., Duarte, A.C., 2015. A critical overview of the analytical approaches to the occurrence, the fate and the behavior of microplastics in the environment. Trends Anal. Chem. 65, 47-53 (Feb).

Rochman, C.M., Hentschel, B.T., Teh, S.J., 2014. Long-term sorption of metals is similar among plastic types: implications for plastic debris in aquatic environments. PLoS One 9 (1), e85433 (Jan 15).

Rochman, C.M., Brookson, C., Bikker, Djuric N., Earn, A., Bucci, K., Athey, S., Huntington, A et al., 2019. Rethinking microplastics as a diverse contaminant suite. Environ. Toxicol. Chem. 38 (4), 703-711. https://doi.org/10.1002/etc.4371 (Apr).

Soutar, C.A., Copland, L.H., Thornley, P.E., Hurley, J.F., Ottery, J., Adams, W.G., Bennett, B. 1980. Epidemiological study of respiratory disease in workers exposed to polyvinylchloride dust. Thorax 35 (9), 644-652 (Sep).

Stanton, T., Johnson, M., Nathanail, P., MacNaughtan, W., Gomes, R.L., 2019. Freshwater and airborne textile fibre populations are dominated by 'natural', not microplastic, fibres. Sci. Total Environ. vol. 666, 377-389. https://doi.org/ 10.1016/j.scitotenv.2019.02.278 (May 20, Epub 2019 Feb 18).

Sussarellu, R., et al., 2016. Oyster reproduction is affected by exposure to polystyrene microplastics. Proc. Natl. Acad. Sci. U. S. A. 113, 2430-2435.

Syberg, K., Nielsen, A., Khan, F.R., Banta, G.T., Palmqvist, A., Jepsen, P.M., 2017. Microplastic potentiates triclosan toxicity to the marine copepod Acartia tonsa (Dana). J. Toxicol. Environ. Health A 80 (23-24), 1369-1371. https://doi.org/ 10.1080/15287394.2017.1385046.

Thompson, R.C., Moore, C.J., vom Saal, F.S., Swan, S.H., 2009. Plastics, the environment and human health: current consensus and future trends. Philos. Trans. R. Soc. Lond. Ser. B Biol. Sci. 364, 2153-2166.

Tian, L., Ahmadi, G., 2013. Fiber transport and deposition in human upper tracheobronchial airways. J. Aerosol Sci. 60, 1-20. https://doi.org/10.1016/j.jaerosci.2013.02.001.

Timbrell, V., 1965. The inhalation of fibrous dusts. Ann. N. Y. Acad. Sci. 132 (1), 255-273 https://doi.org/10.1111/j.1749-6632.1965.tb41107.x.

UNEP, 2016. United Nations Environment Programme. Marine Plastic Debris and Microplastics - Global Lessons and Research to Inspire Action and Guide Policy Change. United Nations Environment Programme, Nairobi.
Vandenberg, L.N., Hauser, R., Marcus, M., Olea, N., Welshons, W.V., 2007. Human exposure to bisphenol A (BPA). Reprod. Toxicol. 24 (2), 139-177 (Aug-Sep).

Verschoor, A., 2014. Quick scan and prioritization of microplastic sources and emissions. RIVM Lett. Rep. 2014-015.6.

Vianello, A., Jensen, R.L., Liu, L., Vollertsen, J., 2019. Simulating human exposure to indoor airborne microplastics using a breathing thermal manikin. Sci. Rep. 9 (1), 8670. https://doi.org/10.1038/s41598-019-45054-w (Jun 17).

Wagner, M., Lambert, S. (Eds.), 2018. Freshwater Microplastics. The Handbook of Environmental Chemistry. Springer International Publishing, Cham.

Wardrop, P., Shimeta, J., Nugegoda, D., Morrison, P.D., Miranda, A., Tang, M., et al., 2016. Chemical pollutants sorbed to ingested microbeads from personal care products accumulate in fish. Environ. Sci. Technol. 50 (7), 4037-4044 (Apr 5).

Warheit, D.B., Hart, G.A., Hesterberg, T.W., Collins, J.J., Dyer, W.M., Swaen, G.M.H., Castranova, V., Soiefer, A.I., Kennedy, G.L., 2001. Potential pulmonary effects of man-made organic fiber (MMOF) dusts. Crit. Rev. Toxicol. 31 (6), 697-736. https:// doi.org/10.1080/20014091111965.

Wetherbee, G., Bladwin, A., Ranville, J., 2019. It is raining plastic. US Geological Survey. Open File Report 2019, p. 1048.

Wright, S.L., Kelly, F.J., 2017. Plastic and human health: a micro issue? Environ. Sci. Technol. 51 (12), 6634-6647 (Jun 20).

Wright, S.L., Ulke, J., Font, A., Chan, K.L.A., Kelly, F.J., 2020. Atmospheric microplastic deposition in an urban environment and an evaluation of transport. Environ. Int. 136, 105411. https://doi.org/10.1016/j.envint.2019.105411 (Mar).

Xinhuanet, 2020. China focus: mask makers go all out in fight against novel coronavirus. February, 06. http://www.xinhuanet.com/english/2020-02/06/c_138760527.htm.

Xu, M., Halimu, G., Zhang, Q., Song, Y., Fu, X., Li, Y., Li, Y., Zhang, H., 2019. Internalization and toxicity: a preliminary study of effects of nanoplastic particles on human lung epithelial cell. Sci. Total Environ. 694, 133794. https://doi.org/ 10.1016/j.scitotenv.2019.133794.

Zhang, Q., Wong, J.P.S., Davis, A.Y., Black, M.S., Weber, R.J., 2017. Characterization of particle emissions from consumer fused deposition modeling 3D printers. Aerosol Sci. Technol. 51 (11), 1275-1286. https://doi.org/10.1080/02786826.2017.1342029.

Zhou, Q., Tian, C., Luo, Y., 2017. Various forms and deposition fluxes of microplastics identified in the coastal urban atmosphere. Sci. Bull. 62 (33), 3902e3909.

Zimmermann, L., Dierkes, G., Ternes, T.A., Völker, C., Wagner, M., 2019. Benchmarking the in vitro toxicity and chemical composition of plastic consumer products. Environ. Sci. Technol. 53 (19), 11467-11477. 